\title{
Monochorionic Pseudomonoamniotic Twin Pregnancy Revealing Fetal Demise. A Unique Case
}

\author{
Sotiriou Sotirios ${ }^{1 *}$, Koukoura Ourania ${ }^{1}$, Sofoudis Chrisostomos ${ }^{2}$, Zacharos Nikolaos Marios ${ }^{3}$, Kailas Pangiotis ${ }^{3}$, \\ Daponte Alexandros ${ }^{1}$ and Garas Antonios ${ }^{1}$
}

${ }^{1}$ Department of Obstetrics and Gynecology, University Hospital of Larissa, Greece

${ }^{2}$ Department of Obstetrics and Gynecology, Konstantopoulio General Hospital, Greece

${ }^{3}$ Larisa Medical School, Univesrity of Thessaly, Greece

Submission: September 10, 2020; Published: September 14, 2020

*Corresponding author: Sotiriou Sotirios, Department of Obstetrics and Gynecology, University Hospital of Larissa, Greece

\begin{abstract}
Abstarct
Pseudoamniotic twin pregnancy represents a rare entity throughout current bibliography. It occurs with an incidence less than $1 \%$ of monozygotic pregnancies revealing a significant mortality rate. The disruption of the partitioning membrane in a monoamniotic twin pregnancy consists the performance and function of pseudoamniotic twin gestation. Cord entanglement depicts the most common cause of perinatal mortality in monoamniotic twin pregnancy. Many conducted studies reported incidence up to $70 \%$ concerning cord entanglement with mortality rate up to $50 \%$ in monoamniotic twins respectively.
\end{abstract}

Keywords: Monochorionic twin pregnancy; Pseudomonoamniotic twin pregnancy; Cord entanglement

\section{Introduction}

Twin pregnancy consists presence of fetal co-existence inside the uterine cavity. Usually, represents fertilization of two eggs from two sperms (dizygotic twins), or fertilization of one egg, separation of the gamete and formation of two embryos (Monozygotic Twins) [1]. All conducted studies from current bibliography estimate incidence of twin pregnancy about $2 \%$ of all other pregnancies [2]. This discrepancy not only is strongly associated to an increased risk of prematurity, but also is depending on the additional risks of chorionity. Monochorionic twin pregnancies are susceptible to additional morbidity due to potential for anastomotic placental vessels and resultant Twin-Twin Transfusion Syndrome (TTTS) [3]. Monochorionic-Monoamniotic pregnancies, during ultrasonographic formation depict lack of dividing membrane, resulting in cord entanglement.

Percentage of cord entanglement estimates about 70\% of all twin pregnancies, leading to an increased rate of intrauterine fetal demise. In extremely rare cases in current bibliography, the dividing membrane in a monochorionic twin gestation can rupture ad create a functional Monochorionic-Monoamniotic, or Pseudomonoamniotic pregnancy [4].
Pseudomonoamniotic Twins, as rare ultra-sonographic entity usually express following characteristics:

a) no dividing membrane during two ultrasound examinations

b) same sex twins

c) normal amniotic fluid volume and

d) unrestricted fetal movement.

Case

We present a case of a 40-year-old patient (G3, P2) admitted at our Department, presented with a spontaneous twin pregnancy. Prenatal monitoring with ultrasound examination confirmed a monochorionic twin pregnancy (Figure 1). Ultra sonographic follow up was settled every 2 weeks, in order to diagnose potential MCDA complications (Monochorionic Diamniotic Twins). Ultra sonographic evaluation during $14^{\text {th }}$ week of gestation confirmed the existence of the diving membrane, sign of MonochorionicDiamniotic pregnancies (Figure 2). 


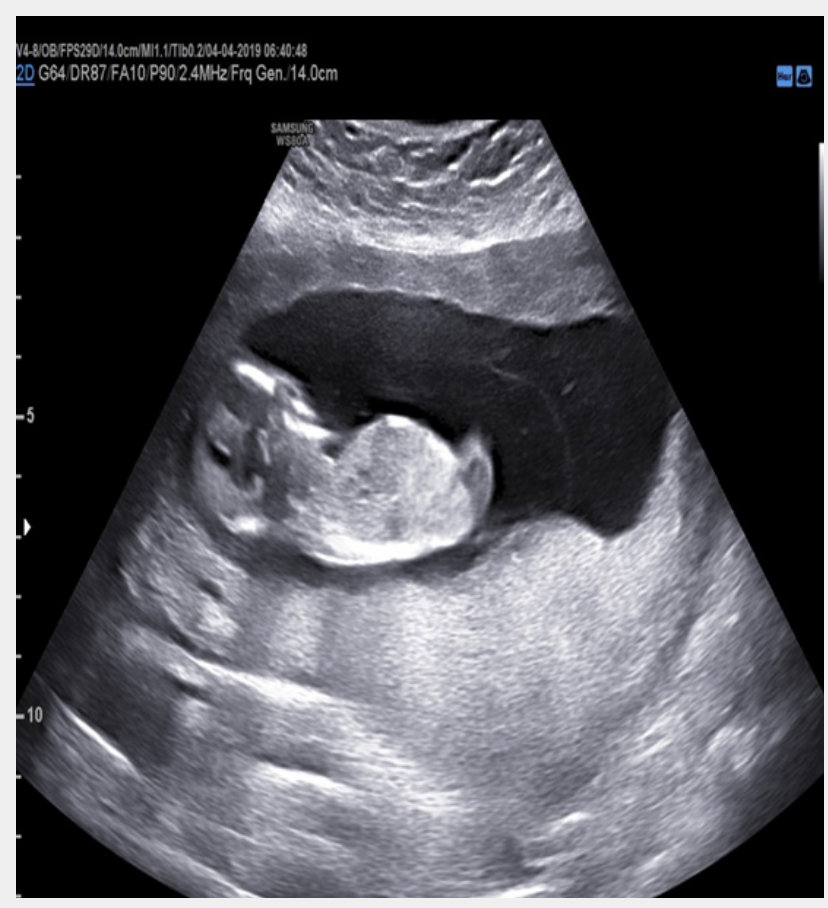

Figure 1: On the right, thin dividing membrane from the two apposed amniotic sacs at 12 week gestation sonogram.

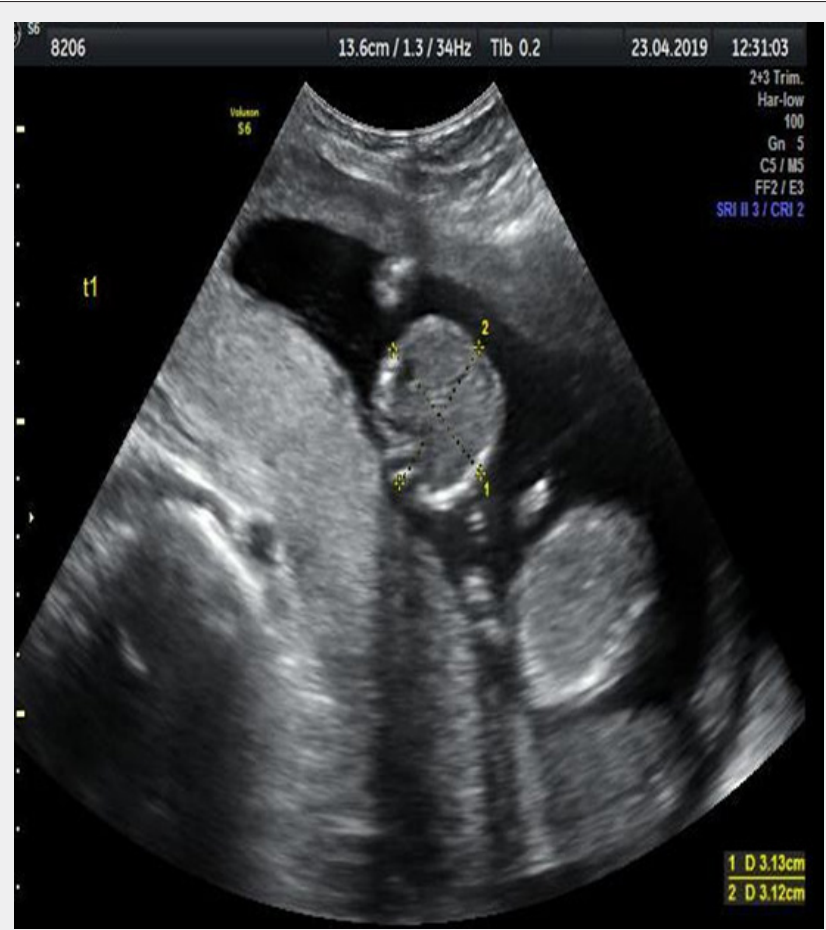

Figure 2: Very thin dividing membrane separating the two amniotic sacs at 14 week gestation sonogram

Ultra sonographic scan during $16^{\text {th }}$ week of gestation revealed normal growth for both embryos, without visualization of the diving membrane. Entanglement of the umbilical cords (Figure 3). Diagnosis of fetal demise during routine ultrasound during $29^{\text {th }}$ week of gestation without any previous complications concerning fetal growth or Doppler assessment. Weekly ultrasonography performance of the other embryo followed by measurement of MCA (Middle Cerebral Artery) maximum velocity index as predictor rate of fetal anemia. MCA v max during 30th week of gestation above $95^{\text {th }}$ centile. 


\section{Journal of Gynecology and Women's Health}

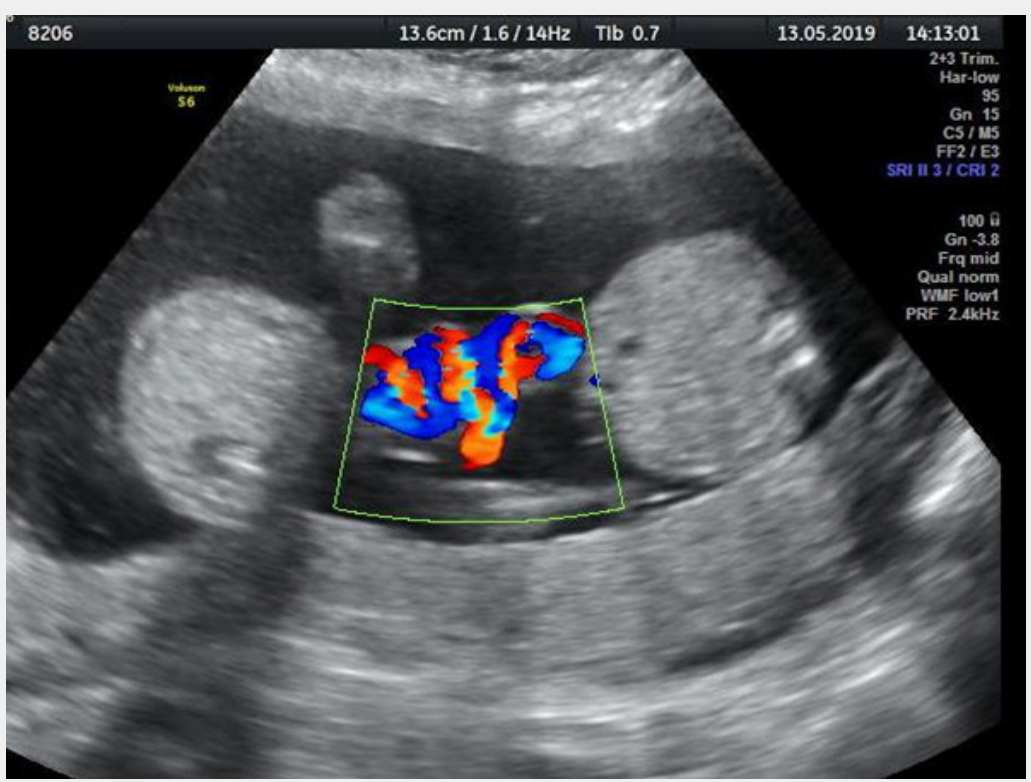

Figure 3: Colour Doppler scan during 16th week of gestation revealed entanglement of the umbilical cords without visualization of the diving membrane.

At 31th week of gestation and after administration of steroid agents concerning fetal lung maturity, patient underwent caesarian section and gave birth of health boy maximum weight of $1900 \mathrm{gr}$. During caesarian section revealed umbilical cords entanglement, presenting evidence of knotting, indicating prenatal disruption of the diving membrane (Figure 4). Neonatal monitoring with serial ultrasound cranial scans and an MRI 4 weeks after delivery did not reveal signs of cerebral hemorrhage.

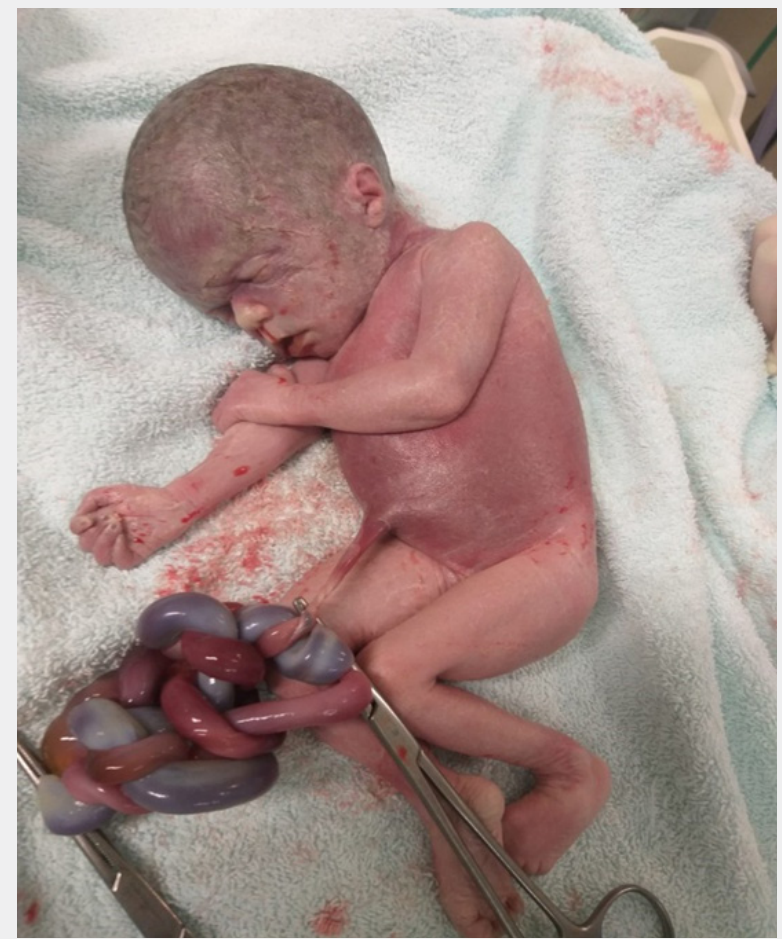

Figure 4: Dead fetus after the caesarian section. Entangled and knotted umbilical cords. The umbilical cords were inserted closely within $2 \mathrm{~cm}$ of each other. 
Histopathologic evaluation confirmed presence of monochorionic diamniotic placenta, followed by a diving membrane between the umbilical cords insertions. Assiduous pathologic and autopsy reports, attributed cause of death of the second twin to entanglement of the umbilical cords, leading to thrombosis of the second twin's umbilical vessels.

\section{Discussion}

Monochorionic pseudomonoamniotic twins represent a very rare entity throughout current bibliography.

Many conducted studies revealed reports of spontaneous and iatrogenic cases of a pseudomonoamniotic twin gestational sac [5]. Monochorionic twin pregnancies are often characterized as high risk pregnancies. Apart elevated prenatal and perinatal mortality rate, monochorionic twin gestations can lead to severe fetal complications.

TTTS (Twin-to-Twin Transfusion Syndrome), TAPS (Twin Anemia Polycythemia Sequence) and TRAP (Twin reversed arterial perfusion) consist the most representative fetal abnormalities [6]. In rare cases of pseudomonoamniotic twins, like our case, cord entanglement is considered the most important causative factor [7]. Incidence of monochorionic twins and correlation with severe congenital abnormalities estimated two or three times more likely, comparing with other gestations [8]. IUGR (Intrauterine Growth Restriction) and SGA (Small for Gestation), often presented in monochorionic twin gestations, are strongly accompanied with fetal hypoxia [9].

Focusing on pathophysiologic evaluation, an impediment in the growth of one twin greatly impacts the well-being of the other. Shared fetal circulation, consists in many cases the pathologic etiology of many complications [10]. Monitoring monochorionic twin fetuses, the deceased fetus may draw blood from living fetus (acute transfusion), associating with severe cerebral injury, due to decreased cerebral blood circulation.

Depending on the pathophysiologic pathways of the monochorionic twin gestations, in our case the surviving fetus was born prematurely in order to avoid severe fetal complications. Ultimate goal of our case consists proper diagnosis and treatment of such cases. Assiduous assessment of the partitioning membrane at each ultrasound monitoring in every monochorionic diamniotic twin gestation, along with cord entanglement depiction, reflect proper recommendations of thorough diagnosis.

\section{Disclosure of Interest}

All authors declare any financial interest with respect to this manuscript.

\section{Conclusion}

Monochorionic pseudomonoamniotic twins reflect rare entities with severe fetal abnormalities. Our case, first described in Greek scientific literature, was properly diagnosed and treated. Ultimate goal remains proper prenatal monitoring, maternal and fetal quality of life respectively.

\section{References}

1. Liu LY, Zafman KB, Fox NS (2020) The Association between Gestational Weight Gain in Each Trimester and Pregnancy Outcomes in Twin Pregnancies. Am J Perinatol.

2. Syngelaki A, Cimpoca B, Litwinska E, Akolekar R, Nicolaides KH, et al. (2019) Diagnosis of fetal defects in twin pregnancies at routine 11-13week ultrasound examination. Obstet Gynecol Sci 62(6): 404-410.

3. Murgano D, Khalil A, Prefumo F, Mieghem TV, Rizzo G, et al. (2020) Outcome of twin-to-twin transfusion syndrome in monochorionic monoamniotic twin pregnancy: systematic review and meta-analysis. Ultrasound Obstet Gynecol 55(3): 310-317.

4. Patil AS, Martin J, Tsukahara K, Skljarevski A, Miller K, et al. (2015) Pseudomonoamniotic Pregnancy: Case Report and Review of Etiologic Considerations. Fetal Pediatr Pathol 34(6): 413-421.

5. Eddib A, Rodgers B, Lawler J, J Yeh (2006) Monochorionic pseudomonoamniotic twin pregnancy with fetal demise of one twin and development of maternal consumptive coagulopathy. Ultrasound Obstet Gynecol 28(5): 736-737.

6. Bamberg C, Hecher K (2019) Update on twin-to-twin transfusion syndrome. Best Pract Res Clin Obstet Gynaecol 58: 55-65.

7. Aisenbrey GA, Catanzarite VA, Hurley TJ, Spiegel JH, Schrimmer DB, et al. (1995) Monoamniotic and pseudomonoamniotic twins: sonographic diagnosis, detection of cord entanglement, and obstetric management. Obstet Gynecol 86(2): 218-222.

8. Townsend R, D'Antonio F, Sileo FG, H Kumbay H, Thilaganathan B, et al. (2019) Perinatal outcome of monochorionic twin pregnancy complicated by selective fetal growth restriction according to management: systematic review and meta-analysis. Ultrasound Obstet Gynecol 53(1): 36-46.

9. Bartha JL, Duyos I, de la Calle M, Herrero B, Rodriguez R, et al. (2019) Severe fetal anemia after umbilical cord occlusion leading to severe neurological injury in monochorionic twins. J Matern Fetal Neonatal Med 11: 1-3.

10. Liao TB, Nomura RM, Liao AW, Francisco RPV, Zugaib M, et al. (2014) Fetal venous circulation in monochorionic twin preganncies with placental insufficiency: prediction of academia at birth or intrauterine fetal death. Ultrasound Obstet Gynecol 43(4): 426-431. 
(C) This work is licensed under Creative DOI: 10.19080/JGWH.2020.19.556023

\section{Your next submission with Juniper Publishers will reach you the below assets}

- Quality Editorial service

- Swift Peer Review

- Reprints availability

- E-prints Service

- Manuscript Podcast for convenient understanding

- Global attainment for your research

- Manuscript accessibility in different formats

( Pdf, E-pub, Full Tsext, Audio)

- Unceasing customer service

Track the below URL for one-step submission

https://juniperpublishers.com/online-submission.php 